\title{
Classic biphasic pulmonary blastoma: importance of early treatment-a case report
}

\author{
Rommel Carrasco, Montserrat Blanco, Daniel Otero, Eva García-Fontán \\ Department of Thoracic Surgery, Vigo University Clinical Hospital, Vigo, Spain \\ Correspondence to: Montserrat Blanco. Department of Thoracic Surgery, Vigo University Clinical Hospital, 36204 Vigo, Spain. \\ Email: montseblancoramos@hotmail.com.
}

\begin{abstract}
Classic biphasic pulmonary blastoma is a very aggressive malignant tumor with very poor prognosis and its overall mortality is very high. It belongs to sarcomatoid neoplasms subgroup in the WHO classification of lung tumors. In the histological analysis shows an immature epithelial and mesenchymal stroma. It is more frequent in middle-age men and can be related with tobacco. Surgery with complete resection is the mainstay of treatment. The role of the chemotherapy or radiotherapy is not very clear because of the rarity and low frequency of this neoplasm. We describe the case of a 63-year-old man that consulted for 2 days history of chest pain and fever. He was diagnosed of a mass of $12 \mathrm{~cm}$ [standardized uptake value (SUV) $6.2 \mathrm{~g} / \mathrm{mL}$ ] in the right hemithorax that was complicated with intratumoral bleeding requiring an emergency surgery because of sudden dyspnea, anemia, hypotension and mediastinal shift. Through a median sternotomy and right anterior thoracotomy a right pneumonectomy was performed. Final classification was pT4N1PL2. The patient received adjuvant chemoradiotherapy that was well tolerated. Overall survival was very good (33 months) because of the multimodal treatment. He presented a recurrence manifested by a mass invading the right ventricle in the 28 -month post-surgery. After three cycles of chemotherapy he died because of progression of the disease 5 months later. With this case report we want to share our experience in the treatment of this infrequent pathology that must be urgently addressed when intratumoral bleeding occurs.
\end{abstract}

Keywords: Pulmonary blastoma; treatment; case report

Received: 11 April 2020; Accepted: 29 June 2020; Published: 25 May 2021.

doi: $10.21037 /$ ccts-20-77

View this article at: http://dx.doi.org/10.21037/ccts-20-77

\section{Introduction}

Classic biphasic pulmonary blastoma (CBPB) is a rare neoplasm of the lung accounting for about $0.25-0.5 \%$ of all primary lung cancers (1). Its histology resembles lung fetal tissue. It predominantly affects adults and generally presents as a large and symptomatic mass causing cough, chest pain, hemoptysis and dyspnea (2). Surgical resection is the treatment of choice for localized disease and the prognosis is very poor (3). We describe this case of special interest due its clinical presentation (hypotension and anemia because of intratumoral bleeding). Surprisingly, overall survival of our patient was 33 months after surgery. We present the following case in accordance with the CARE reporting checklist available at https://ccts.amegroups.com/article/ view/10.21037/ccts-20-77/rc.

\section{Case presentation}

A 63-year-old male without a clinical history of interest was admitted to our institution 48 hours after onset of chest pain and fever. The chest computed tomography (CT) scan revealed the presence of a $12-\mathrm{cm}$ extrapulmonary and heterogeneous mass in the right hemithorax (Figure 1A). A positron emission tomography (PET) scan showed a pathological standardized uptake value (SUV $6.2 \mathrm{~g} / \mathrm{mL}$ ) limited to the mass (Figure 1B). The diagnosis, obtained after a fine-needle aspiration biopsy, was of a biphasic tumor with an epithelial and an undifferentiated mesenchymal 

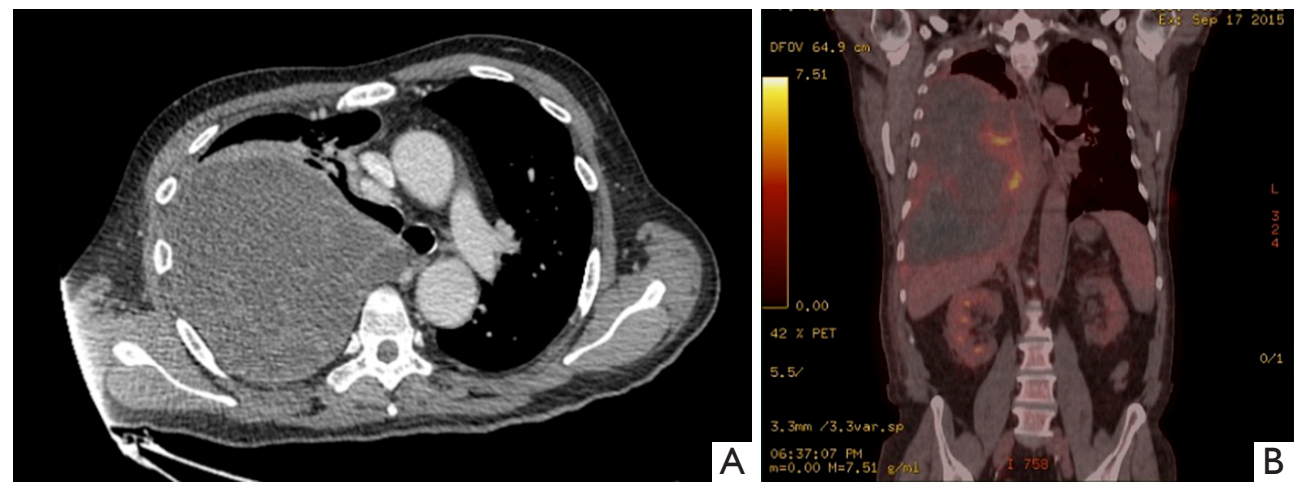

Figure 1 Images of the tumor before surgery. (A) Axial chest CT scan shows a heterogeneous mass with variable contrast enhancement; (B) coronal PET scan with a pathological SUV limited to the mass. CT, computed tomography; PET, positron emission tomography; SUV, standardized uptake value.
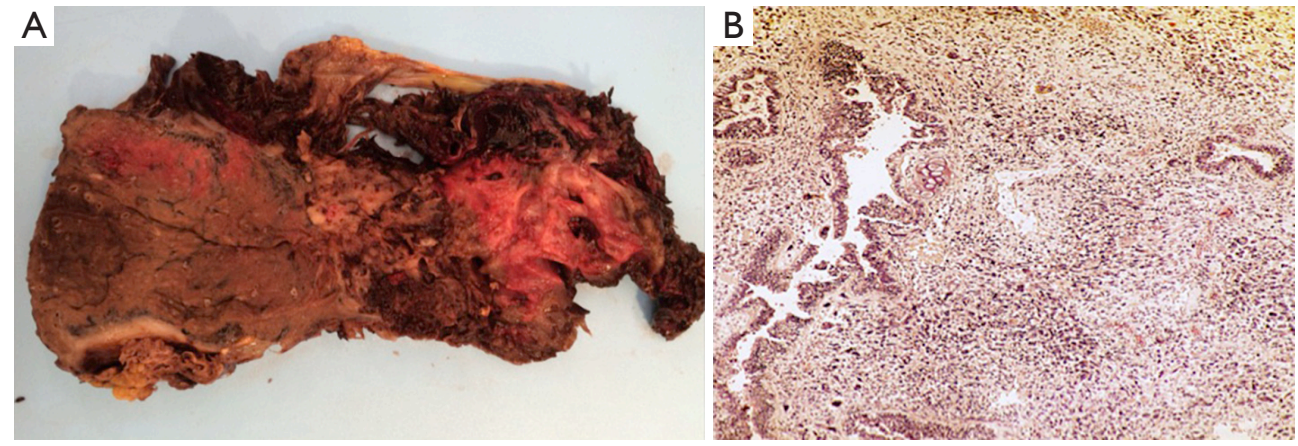

Figure 2 Pathologic examination of the tumor. (A) Surgical specimen fixed in formalin; (B) hematoxylin and eosin staining technique showing the biphasic pattern of the tumor $(20 x)$.

component. During hospitalization, patient's health worsened with the onset of dyspnea on minimal effort, mucocutaneous pallor, hypotension and anemia. A new chest CT scan was performed which revealed intratumoral bleeding and mediastinal shift. Consequently, an emergency surgery was performed through a sternotomy and right anterior thoracotomy; a large mass occupying the right lower lobe with partial infiltration of the middle and upper lobes with spontaneous openings at multiple levels was found. A right pneumonectomy with hilar and mediastinal lymphadenectomy was performed. Postsurgical evolution was satisfactory so the patient was discharged 8 days after surgery. Pathological study revealed a tumor with a $20 \mathrm{~cm} \times 17 \mathrm{~cm}$ diameter and extended areas of necrosis (Figure 2A), microscopical study revealed a typical biphasic component (Figure 2B). Surgical margins were negative. One of ten $(1 / 10)$ hilar nodes presented metastasis of the tumor and was staged pT4N1PL2 according to the $7^{\text {th }}$
TNM classification. EGFR mutations, ALK and ROS1 translocations were negative. The PD-L1 expression was $<1 \%$. The patient received adjuvant chemotherapy (cisplatin and etoposide) and radiotherapy. Adherence and tolerability of chemoradiotherapy was excellent without existing adverse events. During a follow-up chest CT scan 28 months after the surgery, a mediastinal mass invading the right ventricle was found. A CT guided biopsy confirmed the recurrence and the patient received 3 additional cycles of chemotherapy. After the third cycle a chest CT scan showed progression of the disease and the patient died 5 months after the recurrence. In Figure 3, we can observe a timeline that shows the process from the first symptoms to the death of the patient. All procedures performed in this study were in accordance with the ethical standards of the institutional and national research committees and with the Helsinki Declaration (as revised in 2013). Written informed consent was obtained from the patient for publication of 


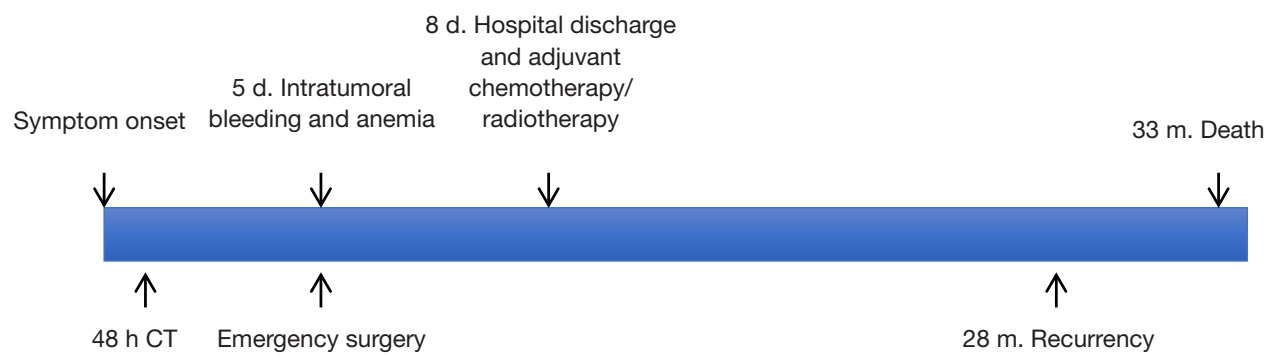

Figure 3 Timeline covering the whole procedure from first symptoms to death. CT, computed tomography.

this case report and any accompanying images. A copy of the written consent is available for review by the editorial office of this journal.

\section{Discussion}

$\mathrm{CBPB}$ is a rare, aggressive and malignant tumor with distinctive biological behaviour (1). Barrett and Barnard first described it in 1945 (4) and were designated as "embryoma of the lung" by Barnard in 1952 (5). According to the 2015 WHO classification of lung tumors, CBPB is considered part of the sarcomatoid carcinoma subgroup (6). Morphologically, it resembles a first trimester fetal lung, is a biphasic tumour characterized by a histological heterogeneity of mixed epithelial and mesenchymal stroma, both components are immature and malignant. Van Loo et al. reported an average age at diagnosis of 39 years with an increased frequency in males (1.5:1) (2). Larsen and Sorensen reported a bimodal age distribution, one peak in the first and one in the seventh decade of life (7), as in our case. It typically presents with cough, chest pain, dyspnea or hemoptysis; although $40 \%$ of patients are asymptomatic at diagnosis.

The etiology remains uncertain. About $80 \%$ of patients have a history of tobacco use (8). A p53 gene mutation with or without $\mathrm{p} 53$ protein overproduction has been linked to CBPB (9). Hansen et al. reported an expression of KIT (CD117) in both components suggesting that CBPB may derive from a single pluripotential cell (10). Chest CT scans typically demonstrates a unilateral and peripheral mixed solid and cystic mass, well-circumscribed, which can be enhanced by contrast $(3,11)$. Preoperative diagnosis by bronchoscopy, fine needle aspiration and CT-guided tumor biopsy has been found to be of limited value due to the pleomorphic pattern and specimens obtained are generally too small to fully characterize this neoplasm. Immunohistochemistry plays a vital role in the diagnosis (12).
Surgical resection is the treatment of choice for localized disease (13). Because of the rarity of the tumor, there is no agreement on adjuvant chemoradiotherapy, but cisplatin is often used due to its efficacy with primitive tumors (2). Some authors have recommended cisplatin and etoposide as adjuvant regimen $(14,15)$. In this way, our patient received 4 cycles of chemotherapy that were well tolerated. Recently, Bosch-Barrera et al. (16) reported the case of a CBPB with intense positive expression of PD-L1 that can lead to a new treatment approach for this neoplasm, our patient's expression of PD-L1 was $<1 \%$, therefore he didn't received immunotherapy as a complementary treatment.

Prognosis is poor with two thirds of patients dying within 2 years after diagnosis and is determined by recurrence, gross size of the tumor $(>5 \mathrm{~cm})$ and presence of metastasis at diagnosis (3). It has a high incidence of recurrence (43\%) within the first year after treatment and a propensity for metastasizing to the mediastinum, pleura, diaphragm, liver, heart and soft tissues and brain $(2,7,17,18)$.

The strength of this case lies in the long survival obtained because of a multimodal treatment. The limitation resides in being a case report, because is something exceptional based in a comment of a single patient.

\section{Conclusions}

CBPB is rare and aggressive neoplasm. It is important for early treatment, not only to obtain a better survival but to avoid complications such as those presented in our case like intratumoral bleeding. Although the role of adjuvance is not clear, we firmly believed that in our case it was a key factor to obtain a long survival.

\section{Acknowledgments}

Funding: None. 


\section{Footnote}

Reporting Checklist: The authors have completed the CARE reporting checklist. Available at https://ccts.amegroups. com/article/view/10.21037/ccts-20-77/rc

Conflicts of Interest: All authors have completed the ICMJE uniform disclosure form (available at https://ccts. amegroups.com/article/view/10.21037/ccts-20-77/coif). The authors have no conflicts of interest to declare.

Ethical Statement: The authors are accountable for all aspects of the work in ensuring that questions related to the accuracy or integrity of any part of the work are appropriately investigated and resolved. All procedures performed in this study were in accordance with the ethical standards of the institutional and national research committees and with the Helsinki Declaration (as revised in 2013). Written informed consent was obtained from the patient for publication of this case report and any accompanying images. A copy of the written consent is available for review by the editorial office of this journal.

Open Access Statement: This is an Open Access article distributed in accordance with the Creative Commons Attribution-NonCommercial-NoDerivs 4.0 International License (CC BY-NC-ND 4.0), which permits the noncommercial replication and distribution of the article with the strict proviso that no changes or edits are made and the original work is properly cited (including links to both the formal publication through the relevant DOI and the license). See: https://creativecommons.org/licenses/by-nc-nd/4.0/.

\section{References}

1. Francis D, Jacobsen M. Pulmonary blastoma. Curr Top Pathol 1983;73:265-94.

2. Van Loo S, Boeykens E, Stappaerts I, et al. Classic biphasic pulmonary blastoma: a case report and review of the literature. Lung Cancer 2011;73:127-32.

3. Koss MN, Hochholzer L, O'Leary T. Pulmonary blastomas. Cancer 1991;67:2368-81.

4. 4Barrett NR, Barnard WG. Some unusual thoracic tumors. Br J Surg 1945;32:447-57.

5. Barnard WG. Embryoma of lungs. Thorax 1952;7:299-301.

6. Travis WD, Brambilla E, Nicholson AG, et al. The 2015 World Health Organization Classification of Lung Tumors: Impact of Genetic, Clinical and Radiologic Advances Since the 2004 Classification. J Thorac Oncol
2015;10:1243-60.

7. Larsen H, Sørensen JB. Pulmonary blastoma: a review with special emphasis on prognosis and treatment. Cancer Treat Rev 1996;22:145-60.

8. Zaidi A, Zamvar V, Macbeth F, et al. Pulmonary blastoma: medium-term results from a regional center. Ann Thorac Surg 2002;73:1572-5.

9. Bodner SM, Koss MN. Mutations in the $\mathrm{p} 53$ gene in pulmonary blastomas: immunohistochemical and molecular studies. Hum Pathol 1996;27:1117-23.

10. Hansen T, Bittinger F, Kortsik C, et al. Expression of KIT (CD117) in biphasic pulmonary blastoma. Novel data on histogenesis. Lung 2003;181:193-200.

11. Nemeh F, Kuo AH, Ross J, et al. The Radiologic and Pathologic Diagnosis of Biphasic Pulmonary Blastoma. J Radiol Case Rep 2017;11:10-21.

12. Yang $M$, Li B, Zhang C, et al. Classical biphasic pulmonary blastoma in a young woman: case report and review of literature. Int J Clin Exp Pathol 2019;12:4400-4.

13. Adluri RK, Boddu SR, Martin-Ucar A, et al. Pulmonary blastoma--a rare tumor with variable presentation. Eur J Cardiothorac Surg 2006;29:236-9.

14. Cutler CS, Michel RP, Yassa M, et al. Pulmonary blastoma: case report of a patient with a 7 -year remission and review of chemotherapy experience in the world literature. Cancer 1998;82:462-7.

15. Magistrelli P, D'Ambra L, Berti S, et al. Adult pulmonary blastoma: Report of an unusual malignant lung tumor. World J Clin Oncol 2014;5:1113-6.

16. Bosch-Barrera J, Holguin F, Baldó X, et al. Neoadjuvant Chemoradiotherapy Treatment for a Classic Biphasic Pulmonary Blastoma with High PD-L1 Expression. Anticancer Res 2015;35:4871-5.

17. Xiu Y, Jiang L, Liu W. Classic biphasic pulmonary blastoma with brain and axillary metastases: a case report with molecular analysis and review of literature. Int J Clin Exp Pathol 2015;8:983-8.

18. Kilic D, Yilmaz C, Tepeoglu M, et al. Biphasic Pulmonary Blastoma Associated with Cerebral Metastasis. Turk Neurosurg 2016;26:169-72.

doi: $10.21037 /$ ccts-20-77

Cite this article as: Carrasco R, Blanco M, Otero D, GarcíaFontán E. Classic biphasic pulmonary blastoma: importance of early treatment-a case report. Curr Chall Thorac Surg 2021;3:19. 